\title{
A time-resolved microwave conductivity study of the optoelectronic processes in $\mathrm{TiO}_{2}\left|\ln _{2} \mathrm{~S}_{3}\right|$ CulnS $_{2}$ heterojunctions
}

\author{
Tom J. Savenije ${ }^{\text {a) }}$ and Marian Nanu \\ OptoElectronic Materials Section, Department of DelftChemTech, Faculty of Applied Sciences, \\ Delft University of Technology, Julianalaan 136, 2628 BL Delft, The Netherlands \\ Joop Schoonman \\ Delft Institute for Renewable Energy, Faculty of Applied Sciences, Delft University of Technology, \\ Julianalaan 136, 2628 BL Delft, The Netherlands

\begin{abstract}
Albert Goossens
OptoElectronic Materials Section, Department of DelftChemTech, Faculty of Applied Sciences,
\end{abstract} \\ Delft University of Technology, Julianalaan 136, 2628 BL Delft, The Netherlands
}

(Received 21 March 2007; accepted 24 April 2007; published online 15 June 2007)

\begin{abstract}
Photoinduced interfacial charge carrier generation, separation, trapping, and recombination in $\mathrm{TiO}_{2}\left|\mathrm{In}_{2} \mathrm{~S}_{3}\right| \mathrm{CuInS}_{2}$ cells have been studied with time-resolved microwave conductivity (TRMC). Single layer, double layer, and complete triple layer configurations have been studied. Selective electronic excitation in one of the components is accomplished by using monochromatic pulsed laser excitation. In bare CuInS $S_{2}$ films and in $\mathrm{TiO}_{2} \mid \mathrm{CuInS}_{2}$ double layers, photoinduced charge carriers recombine on a subnanosecond time scale. This fast recombination slows down significantly when an $\mathrm{In}_{2} \mathrm{~S}_{3}$ buffer layer is applied between $\mathrm{TiO}_{2}$ and $\mathrm{CuInS}_{2}$. In that case, the charge separation lifetime increases by more than one order of magnitude. A superlinear dependence of the TRMC signals on the incident laser intensity is observed for the triple layer configuration, which indicates saturation of electron traps in $\mathrm{In}_{2} \mathrm{~S}_{3}$ or hole traps in $\mathrm{CuInS}_{2}$. Furthermore, TRMC signals from $\mathrm{TiO}_{2}\left|\mathrm{In}_{2} \mathrm{~S}_{3}\right| \mathrm{CuInS}_{2}$ triple junctions and those from $\mathrm{In}_{2} \mathrm{~S}_{3} \mid \mathrm{CuInS}_{2}$ double layers are identical, which shows that charge carrier separation exclusively takes place at the $\mathrm{In}_{2} \mathrm{~S}_{3} \mid \mathrm{CuInS}_{2}$ interface. (C) 2007 American Institute of Physics. [DOI: 10.1063/1.2745386]
\end{abstract}

\section{INTRODUCTION}

Thin film solar cells based on chalcogenides, such as $\mathrm{Cu}(\mathrm{In}, \mathrm{Ga}) \mathrm{Se}_{2}$ and $\mathrm{CuInS}_{2}$, are widely studied because of their great potential to replace silicon photovoltaic (PV) cells in due time. While present solar panels are mostly made from crystalline silicon, it is believed that thin film chalcogenide PV cells will concur a large marked share in the coming decade. PV cells made from $\mathrm{Cu}(\mathrm{In}, \mathrm{Ga}) \mathrm{Se}_{2}$ (CIGSe) and $\mathrm{CuInS}_{2}$ (CIS) can be made with relative cheap deposition techniques in a large-scale industrial process, which reduces the production costs and the energy payback time of these cells considerably. More information on the present status of chalcopyrite solar cells is available in the recent book by Siebentritt and Rau. ${ }^{1}$

A disadvantage of today's CIGSe and CIS cells is the need of cadmium containing, i.e., CdS, buffer layer. Obviously, there is a great incentive to replace $\mathrm{CdS}$ by a less hazardous material. $\mathrm{In}_{2} \mathrm{~S}_{3}$ and $\mathrm{ZnS}$ are considered as good alternatives and are presently under thorough investigation. The function of the buffer layer in CIGSe and CIS solar cells is not completely understood yet. Having a typical thickness of only $50 \mathrm{~nm}$, the optoelectronic properties of the buffer layer, in particular, in relation with the absorber materials, are very difficult to assess experimentally.

Furthermore, a solar cell concept has been introduced

${ }^{a)}$ Electronic mail: t.j.savenije@tudelft.nl recently in which $n$ - and $p$-type semiconductors are mixed on a nanometer scale to form a "3D solar cell." ${ }^{,-7}$ This nanocomposite configuration may offer opportunities for reducing the amount of material, enhancing the conversion efficiency, and simplifying the production process, as has been demonstrated with C60-polymer bulk heterojunctions. ${ }^{8}$

The operation principle of most CIS solar cells is based on (i) the optical excitation of $p$-type CIS, (ii) the charge separation at the interface with the $n$-type wide band-gap buffer material, and (iii) the migration of charge carriers to the front and back electrodes. In Fig. 1 these processes are schematically presented. The energy conversion efficiency is governed by several internal processes, as indicated in Fig. 1. First there are the generation (1) and recombination (2) of electron-hole pairs in CIS. In addition there are several inter-

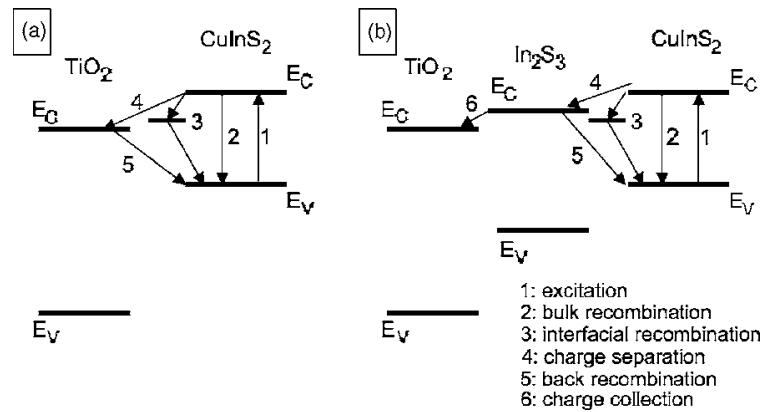

FIG. 1. Band diagram of a double layer (a) and a triple layer configuration (b). Possible carrier generation and recombination processes are indicated. 
face related processes. Process 3 is recombination in CIS due to the presence of interface states. Processes 4 and 5 relate to the heterogeneous electron transfer (4) and back reaction (5). Finally, for the triple junction, process 6 is electron transfer from the buffer material into the electron collecting $\mathrm{TiO}_{2} .{ }^{9,10}$

In a nanocomposite three-dimensional (3D) solar cell, blending of the materials implies a large internal surface area, which facilitates interfacial processes $3-5$. In this regard it seems disadvantageous to introduce a large internal contact area. However, recent studies have shown that 3D solar cells of $n$-type $\mathrm{TiO}_{2}$ and $p$-type CIS can be made by atomic layer deposition (ALD). ${ }^{11,12}$ Without the application of a buffer layer, the conversion efficiencies are very poor, but when a thin film of $\mathrm{In}_{2} \mathrm{~S}_{3}$ is introduced in between $\mathrm{TiO}_{2}$ and $\mathrm{CuInS}_{2}$ a significant increase of the energy conversion efficiency is found. ${ }^{2,7}$ In a $3 \mathrm{D}$ cell the thickness of the buffer layer is only $5-10 \mathrm{~nm}$ and it is surprising that such a thin film has such a large effect.

The present investigations focus on the role of the $\operatorname{In}_{2} \mathrm{~S}_{3}$ buffer layer in $\mathrm{TiO}_{2}\left|\operatorname{In}_{2} \mathrm{~S}_{3}\right|$ CIS solar cells. Toward this end, the photophysical processes in thin films of $\mathrm{TiO}_{2}, \mathrm{In}_{2} \mathrm{~S}_{3}$, and CIS are investigated with time-resolved microwave conductivity (TRMC). Single layers, all double layer combinations, and the complete $\mathrm{TiO}_{2}\left|\mathrm{In}_{2} \mathrm{~S}_{3}\right| \mathrm{CuInS}_{2}$ configuration are studied. To allow accurate quantitative analysis of the data, only flat films and not the 3D nanocomposites are studied here. In all cases, quartz serves as a substrate material to suppress background microwave absorption. TRMC offers the advantage over many other characterization techniques by being a contactless method. ${ }^{13-16}$ After applying pulsed laser excitation, the time-resolved absorption of microwaves by mobile charge carriers is used to determine the lifetime of the charge-separated state. Since the involved materials have different band gaps, selective excitation can be applied. In addition to temporal information, from the magnitude of the TRMC signals the sum of the mobilities of the positive and negative charges can be derived. ${ }^{17}$ The use of TRMC to study the interfacial electronic processes in CIS solar cells has never been reported before. Yet, we demonstrate that indeed this technique provides valuable information about fundamental internal processes that are difficult, or impossible, to determine otherwise.

\section{EXPERIMENTAL ASPECTS}

Dense films of $\mathrm{TiO}_{2}(\sim 100 \mathrm{~nm})$ have been applied onto $1 \mathrm{~mm}$ thick quartz plates by chemical spray pyrolysis. For the dc current-voltage measurements, the quartz substrate is replaced with $\mathrm{SnO}_{2}$ coated glass and $2 \mathrm{~mm}$ gold spots are applied as back contacts. A mixture consisting of $54 \mathrm{ml}$ ethanol (99.99\%), $3.6 \mathrm{ml}$ acetyl acetonate (99\%), and $2.4 \mathrm{ml}$ titanium tetraisopropoxide (97\%) is sprayed on the quartz substrate, which is kept at a constant temperature of $350{ }^{\circ} \mathrm{C}$. The buffer material $\mathrm{In}_{2} \mathrm{~S}_{3}$ and the absorber $\mathrm{CuInS}_{2}$ are deposited by ALD using $\mathrm{CuCl}$ (99.999\%), $\mathrm{InCl}_{3}$ (99.999\%), and $\mathrm{H}_{2} \mathrm{~S}$ as precursors. The deposition temperature for $\mathrm{In}_{2} \mathrm{~S}_{3}$ deposition is $450{ }^{\circ} \mathrm{C}$, which is lowered to $400{ }^{\circ} \mathrm{C}$ for CIS deposition. In both cases the reactor pressure is 7 mbars. The ALD deposition of $\operatorname{In}_{2} \mathrm{~S}_{3}$ and CIS films has been described elsewhere. ${ }^{11}$ The thickness of the various layers is calculated from the number of ALD cycles and amounts to $100 \mathrm{~nm}$ for $\mathrm{TiO}_{2}, 50 \mathrm{~nm}$ for $\operatorname{In}_{2} \mathrm{~S}_{3}$, and $100 \mathrm{~nm}$ for CIS for the double layer and triple layer configurations. For the single $\operatorname{In}_{2} \mathrm{~S}_{3}$ and CIS layers, the thickness is increased to 400 and $500 \mathrm{~nm}$, respectively. Thermal annealing in sulfur vapor at $500{ }^{\circ} \mathrm{C}$, followed by annealing in oxygen at $200{ }^{\circ} \mathrm{C}$, is performed as a postdeposition treatment. These annealing procedures remove the sulfur vacancies that are created during the ALD growth. Sulfur vacancies form shallow donors and convert the CIS into $n$-type material, which is undesirable.

Current-voltage $(I-V)$ curves are recorded in the dark and under illumination with a potentiostat (EGG, model 273) and a calibrated solar simulator (SolarConstant 1200, K.H. Steuernagel Lichttechnik $\mathrm{GmbH}$ ). The photoresponse of the cells is monitored with a dc source meter (Keithley, model 2400) in combination with a monochromatic light source, consisting of a $250 \mathrm{~W}$ halogen lamp and a monochromator (S275, Acton Research Corp.). Always a shadow mask is used for the irradiation and the light intensity is calibrated with a photodiode (Ophir-Nova). The incident photon to current conversion efficiency (IPCE) (or external quantum efficiency) is calculated from the photocurrent divided by the incident photon flux, uncorrected for reflective losses or optical absorption by the conducting glass.

The transmission and reflection spectra of the films are recorded with a Perkin-Elmer Lambda 900 spectrophotometer equipped with an integrating sphere (Labsphere). The optical densities (absorption spectra) corrected for reflections are obtained from

$$
\mathrm{OD}=-\log _{10}\left(\frac{I_{t}}{I_{0}-I_{r}}\right)
$$

in which $I_{t}$ is the transmitted, $I_{0}$ the incident, and $I_{r}$ the reflected light intensities. The "attenuation spectra," denoting the fraction of absorbed photons $\left(F_{A}\right)$, are calculated from

$$
F_{A}=1-\left(\frac{I_{t}+I_{r}}{I_{0}}\right) .
$$

In the TRMC experiments, the samples are photoexcited at $\lambda=300,450$, or $650 \mathrm{~nm}$ using a $Q$-switched Nd:YAG (yttrium aluminum garnet) laser (Infinity, Coherent) in conjunction with an optical paramagnetic oscillator (OPO) and a second harmonic generating (SHG) crystal for $300 \mathrm{~nm}$ irradiation. Pulses with a typical intensity of $20 \mu \mathrm{J} / \mathrm{cm}^{2}$ per pulse and $\sim 3 \mathrm{~ns}$ full width at half maximum (FWHM) are applied, always passing the quartz substrate first, unless stated otherwise.

The incident intensity is measured with a Labmaster power meter (Coherent) having a pyroelectric sensor. The light enters the microwave cell via a grid in the metal end plate. The amplitude change of the reflected $8.5 \mathrm{GHz}$ microwaves following laser excitation is monitored using microwave circuitry and detection equipment, as has been described elswhere. ${ }^{18,19}$ Transients are recorded with a Lecroy LT374L digitizer and the overall time response of the setup is $\sim 1 \mathrm{~ns}$. 
The time-dependent change of the microwave power $[\Delta P(t) / P]$ is related to the change in conductance $\Delta G(t)$ of the irradiated film by

$$
\Delta P(t) / P=-K \Delta G(t) .
$$

In Eq. (3), $K$ is the sensitivity factor which is derived from the reflection characteristics of the measuring cell and the dielectric properties of the medium and amounts to 1.0 $\times 10^{3} \mathrm{~S}^{-1} \cdot{ }^{17}$ To compare various samples it is convenient to normalize the TRMC signals with respect to the intensity of the incident laser excitation. Therefore, signals are expressed as $\eta(t) \Sigma \mu$, which is the product of the time-dependent charge carrier density normalized with the incident irradiation intensity $\eta(t)$ and the sum of the mobilities of the positive and negative charge carriers $\Sigma \mu$, and is given by

$$
\eta(t) \Sigma \mu=\frac{[\Delta P(t) / P]}{\operatorname{KeI}_{0} \beta},
$$

where $I_{0}$ is the photon density per pulse (photons $\left./ \mathrm{m}^{2}\right), \beta$ $=2.1$ corresponding to the ratio of the rectangular dimensions of the waveguide used, and $e$ is the elementary charge. If recombination of charge carriers during the laser pulse is absent, the maximum observed value of $\eta\left(\eta_{\max }\right)$ equals the external charge carrier generation quantum efficiency.

\section{RESULTS AND DISCUSSION}

The current-voltage curves in the dark and under $1000 \mathrm{~W} \mathrm{~m}^{-2}$ (AM 1.5) simulated solar light of a cell comprising of $\mathrm{SnO}_{2}: \mathrm{F}\left|\mathrm{TiO}_{2}\right| \mathrm{In}_{2} \mathrm{~S}_{3}|\mathrm{CIS}|$ gold are presented in Fig. 2(a). In this cell, the film thicknesses are $100 \mathrm{~nm}$ for $\mathrm{TiO}_{2}$, $50 \mathrm{~nm}$ for $\mathrm{In}_{2} \mathrm{~S}_{3}$, and $500 \mathrm{~nm}$ for $\mathrm{CuInS}_{2}$. The IPCE spectrum of this cell is shown in Fig. 2(b). The cells have an open circuit voltage $V_{\mathrm{OC}}$ of $0.52 \mathrm{~V}$, a short circuit current $I_{\mathrm{SC}}$ of $28 \mathrm{~mA} / \mathrm{cm}^{-2}$, and a fill factor of 0.52 .

Figure 3 shows the optical densities of the $\mathrm{TiO}_{2}$, $\mathrm{TiO}_{2} \mid \mathrm{In}_{2} \mathrm{~S}_{3}$, and $\mathrm{TiO}_{2}\left|\mathrm{In}_{2} \mathrm{~S}_{3}\right| \mathrm{CuInS}_{2}$ thin film configurations. The absorption spectrum of $\mathrm{TiO}_{2}$ anatase shows a strong absorption in the UV region. The $\mathrm{TiO}_{2} \mid \mathrm{In}_{2} \mathrm{~S}_{3}$ combination has an additional absorption with an onset at $520 \mathrm{~nm}$. The three-layer $\mathrm{TiO}_{2}\left|\mathrm{In}_{2} \mathrm{~S}_{3}\right| \mathrm{CuInS}_{2}$ configuration shows optical absorption starting at $900 \mathrm{~nm}$. The absorption coefficient for CIS, as derived from the optical density and the film thickness, closely matches the literature data and shows that ALD deposited CIS is of excellent quality. ${ }^{20}$

\section{Single layers}

By applying the appropriate photoexcitation wavelength, the optoelectronic behavior of each of the components can be studied separately. In Figs. 4(a)-4(c), the TRMC signals for single films of $\mathrm{TiO}_{2}, \mathrm{In}_{2} \mathrm{~S}_{3}$, and $\mathrm{CuInS}_{2}$ are shown, respectively, using excitation wavelengths of 300,450 , and $650 \mathrm{~nm}$. The rise and decay of the TRMC signals reflects the various processes that appear, as discussed above. However, due to the limited time resolution of our system $(\approx 1 \mathrm{~ns})$, it is impossible to monitor the generation of the charge carriers. Trapping and recombination of electrons and holes occur on longer time scales and lead to the decay of the TRMC signals. TRMC signals are deconvoluted with the 3 ns laser
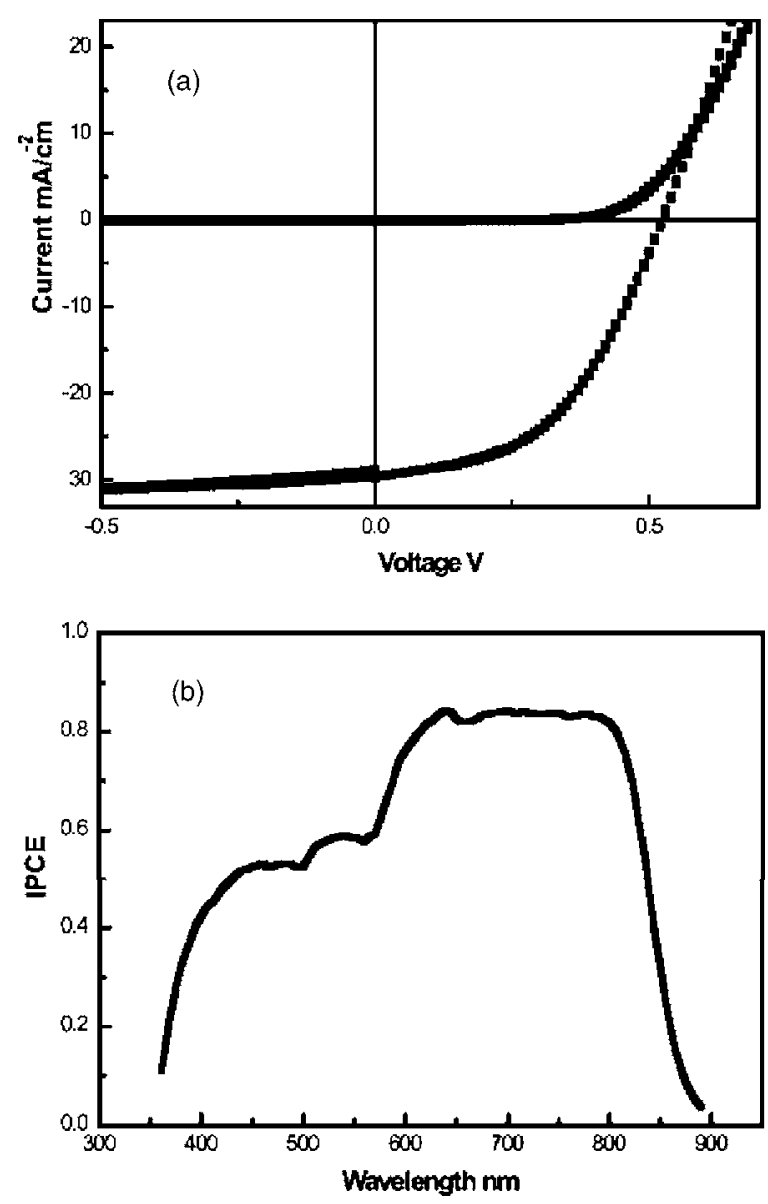

FIG. 2. I-V characteristics of a $\mathrm{TiO}_{2}\left|\operatorname{In}_{2} \mathrm{~S}_{3}\right| \mathrm{CuInS}_{2}$ solar cell in the dark and under illumination (a) and the corresponding incident photon to current efficiency (b).

pulse and the 1 ns instrument response time and then fitted to a single or a biexponential function, yielding characteristic decay times $\tau_{i}$ which are presented in Table I for all the investigated configurations.

For anatase $\mathrm{TiO}_{2}$ [Fig. 4(a)] TRMC signals are only observed with excitation of $300 \mathrm{~nm}$ because of its $3.2 \mathrm{eV}$ band gap. Correcting the maximum observed $\eta \Sigma \mu$ signal with the

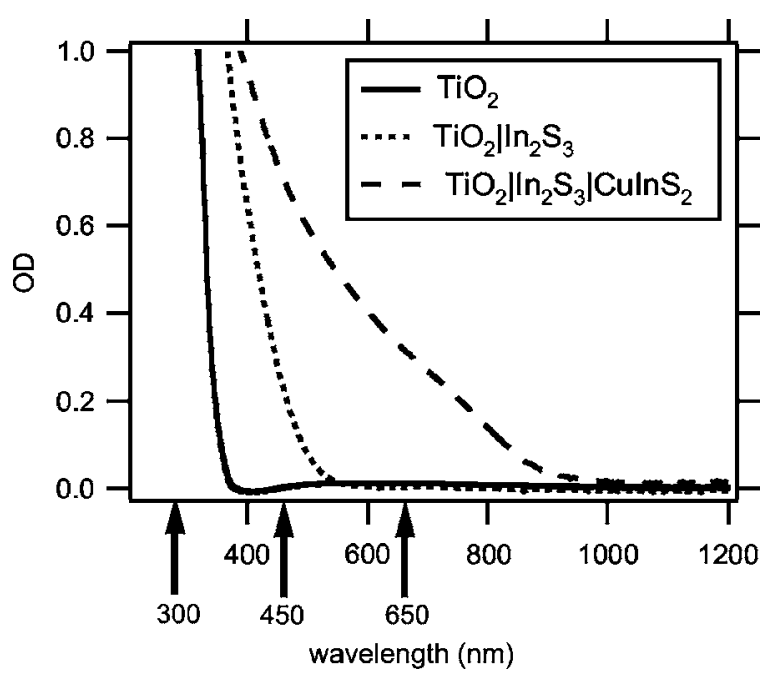

FIG. 3. Optical absorption spectra of various samples on quartz substrates. Arrows indicate the excitation wavelengths used in TRMC experiments. 


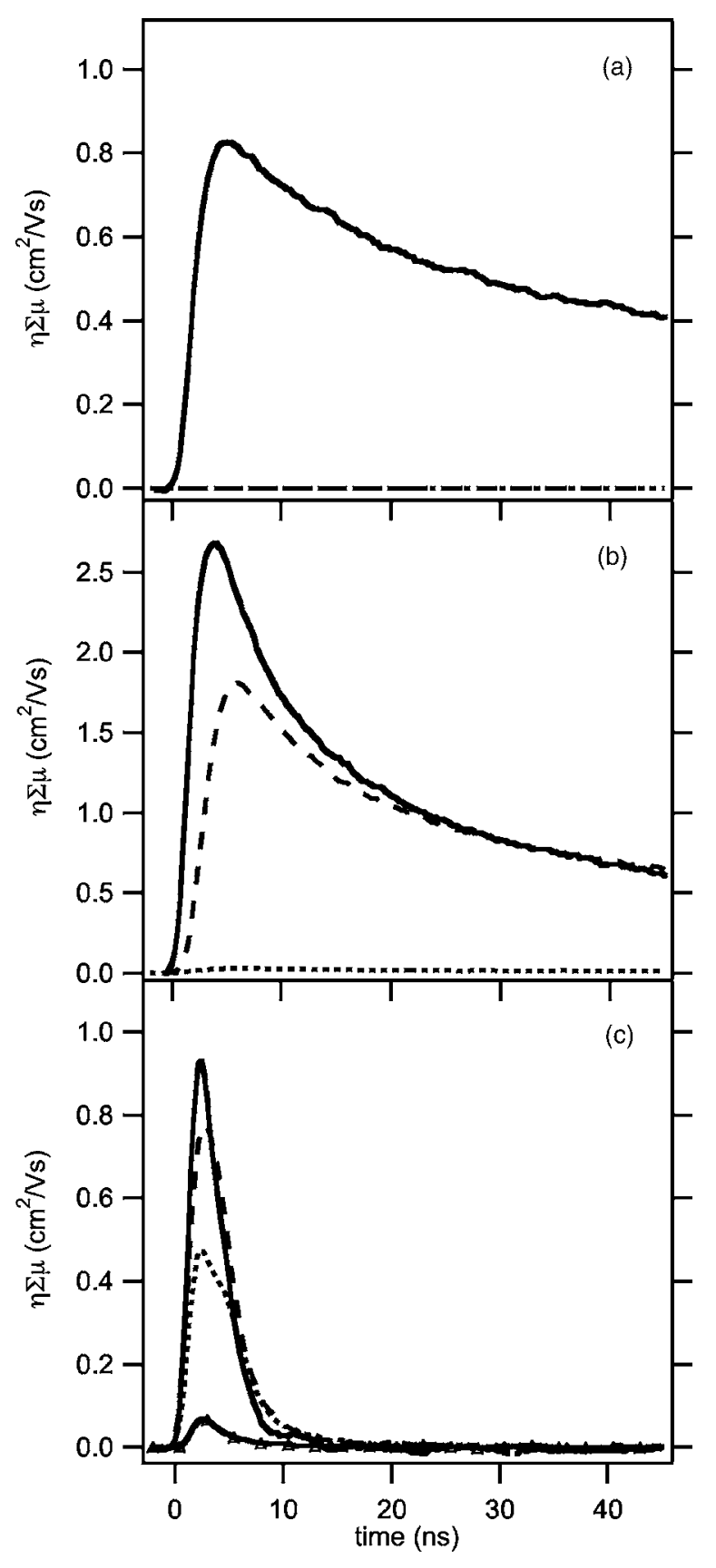

FIG. 4. TRMC response for individual layers of $\mathrm{TiO}_{2}$ (a), $\mathrm{In}_{2} \mathrm{~S}_{3}$ (b), and $\mathrm{CuInS}_{2}$ (c) at $300 \mathrm{~nm}$ (solid), $450 \mathrm{~nm}$ (dashed), and $650 \mathrm{~nm}$ (dotted) at an incident intensity of $20 \mu \mathrm{J} / \mathrm{cm}^{2}$ pulse. For CuInS 2 also excitation from the front side at $\lambda=300 \mathrm{~nm}$ has been included, indicated by the triangles.

optical attenuation of 0.63 at $300 \mathrm{~nm}$ and assuming an electron-hole pair formation efficiency close to unity, a $\Sigma \mu$ of $1.3 \mathrm{~cm}^{2} \mathrm{~V}^{-1} \mathrm{~s}^{-1}$ is found, which matches well with reported values for the mobility of conduction band electrons in anatase $\mathrm{TiO}_{2}{ }^{21,22}$ The major part of the TRMC signal shows a long decay time of $90 \mathrm{~ns}$.

Due to its band gap of $2.1 \mathrm{eV}, \operatorname{In}_{2} \mathrm{~S}_{3}$ absorbs laser pulses of 300 and $450 \mathrm{~nm}$, yielding TRMC signals with two decay times, i.e., 5-6 and 50-60 ns, as shown in Fig. 4(b). These long lifetimes indicate that trapping and recombination rates are low, suggesting a good film quality. This is corroborated by the high value of $\Sigma \mu$, which amounts to $5.2 \mathrm{~cm}^{2} \mathrm{~V}^{-1} \mathrm{~s}^{-1}$ when unity external quantum efficiency is assumed. This value is close to the charge carrier mobilities of $n$-type $\operatorname{In}_{2} \mathrm{~S}_{3}$ reported previously. ${ }^{23,24}$

Finally, $\mathrm{CuInS}_{2}$ absorbs all three wavelengths due to its $1.55 \mathrm{eV}$ band gap. Figure 4(c) shows that the charge carrier lifetime of $\mathrm{CuInS}_{2}$ is much shorter than those of $\mathrm{TiO}_{2}$ and $\mathrm{In}_{2} \mathrm{~S}_{3}$. The TRMC signals follow approximately the shape of the excitation pulse, implying that trapping or recombination takes place already during the laser pulse. In view of the hole mobility of CIS being $100 \mathrm{~cm}^{2} \mathrm{~V}^{-1}$ (Ref. 25) and the observed maximum values for $\eta \Sigma \mu$ of $0.5-1 \mathrm{~cm}^{2} \mathrm{~V}^{-1} \mathrm{~s}^{-1} \mathrm{di}-$ rectly after the laser pulse, the characteristic decay time is expected to be much less than $1 \mathrm{~ns}$.

Only for CIS films a difference between front side (CISair) and back side (CIS-substrate) excitations is observed. $\eta \Sigma \mu$ is an order of magnitude larger for back side excitation [Fig. 4(c)]. This suggests that the quality of the material is different at the two interfaces, which can be explained by the segregation of $\mathrm{Cu}_{x} \mathrm{~S}$ on the outer surface, which enhances the recombination rate of the photoinduced charge carriers. ${ }^{10,26}$

\section{Double layers}

The photoconductivity transients of double layer combinations $\left(\mathrm{TiO}_{2}\left|\mathrm{CIS}, \mathrm{TiO}_{2}\right| \mathrm{In}_{2} \mathrm{~S}_{3}\right.$, and $\left.\mathrm{In}_{2} \mathrm{~S}_{3} \mid \mathrm{CIS}\right)$, obtained with 300, 450, and $650 \mathrm{~nm}$ excitations are presented in Figs. 5(a)-5(c), respectively. Upon applying $300 \mathrm{~nm}$ excitation, the TRMC signals of $\mathrm{TiO}_{2} \mid \mathrm{CIS}$ and $\mathrm{TiO}_{2} \mid \mathrm{In}_{2} \mathrm{~S}_{3}$ double layers are similar to those of single $\mathrm{TiO}_{2}$ layers. Apparently, the presence of CIS or $\operatorname{In}_{2} \mathrm{~S}_{3}$ on top of $\mathrm{TiO}_{2}$ does not lead to a prolonged lifetime of electron-hole pairs generated in $\mathrm{TiO}_{2}$. The absence of charge separation is in agreement with previous studies on $\mathrm{TiO}_{2} \mid \mathrm{In}_{2} \mathrm{~S}_{3}$ double layers. ${ }^{27,28}$ This is remarkable, since hole transfer between $\mathrm{TiO}_{2}$ and either $\operatorname{In}_{2} \mathrm{~S}_{3}$ or CIS is expected to be fast. A plausible explanation is that since $\mathrm{TiO}_{2}$ and $\mathrm{In}_{2} \mathrm{~S}_{3}$ are both $n$-type materials, ${ }^{24}$ accumulation layers rather than depletion layers are formed, which creates an energy barrier for hole transfer. The same explanation for $\mathrm{TiO}_{2} \mid \mathrm{CIS}$ heterojunctions implies that at this interface CIS has turned into $n$ type. Such type of conversion at the interface is not impossible for CIS and is now under study.

Excitation of the $\mathrm{TiO}_{2} \mid \mathrm{In}_{2} \mathrm{~S}_{3}$ double layers at $450 \mathrm{~nm}$ yields TRMC signals identical to those of a single $\operatorname{In}_{2} \mathrm{~S}_{3}$ layer. Neither charge separation nor interfacial charge recombination seems to occur. Formation of an accumulation layer at $\mathrm{TiO}_{2} \mid \mathrm{In}_{2} \mathrm{~S}_{3}$ junctions again explains this observation well. Electrons accumulate at the $\mathrm{TiO}_{2} \mid \mathrm{In}_{2} \mathrm{~S}_{3}$ interface upon exciting $\mathrm{TiO}_{2}(300 \mathrm{~nm})$ or $\mathrm{In}_{2} \mathrm{~S}_{3}(450 \mathrm{~nm})$, and since the holes are removed quickly from this interface, electron-hole recombination is slow.

The situation is quite different when $\mathrm{TiO}_{2} \mid \mathrm{CIS}$ junctions are excited with 450 and $650 \mathrm{~nm}$ and electron-hole pairs are generated in CIS. Now the observed TRMC signals are even smaller than those of single CIS films. Apparently, the interface between $\mathrm{TiO}_{2}$ and CIS introduces additional recombination paths, i.e., processes 3-5 in Fig. 1. These findings agree well with the low photocurrents observed for $\mathrm{TiO}_{2} \mid \mathrm{CIS}$ double layer cells without $\mathrm{In}_{2} \mathrm{~S}_{3}$ buffer. ${ }^{2,7}$ 
TABLE I. Decay times $(\tau)$ found after deconvolution of the transients with the laser pulse and the instrument response time. A laser pulse intensity of $20 \mu \mathrm{J} / \mathrm{cm}^{2}$ is used at all wavelengths. A dash indicates no detectable signal was observed.

\begin{tabular}{|c|c|c|c|c|c|c|}
\hline \multirow[b]{2}{*}{ Sample } & \multicolumn{2}{|c|}{$300 \mathrm{~nm}$} & \multicolumn{2}{|c|}{$450 \mathrm{~nm}$} & \multicolumn{2}{|c|}{$650 \mathrm{~nm}$} \\
\hline & Prefactor & $\tau_{\lambda}(\mathrm{ns})$ & Prefactor & $\tau_{\lambda}(\mathrm{ns})$ & Prefactor & $\tau_{\lambda}(\mathrm{ns})$ \\
\hline \multirow[t]{2}{*}{$\mathrm{TiO}_{2}$} & 0.36 & 6 & & - & & - \\
\hline & 0.64 & 90 & & & & \\
\hline \multirow[t]{2}{*}{$\mathrm{In}_{2} \mathrm{~S}_{3}$} & 0.63 & 6 & 0.5 & 5 & & - \\
\hline & 0.37 & 50 & 0.5 & 58 & & \\
\hline $\mathrm{CuInS}_{2}$ & & $<1$ & & $<1$ & & $<1$ \\
\hline \multirow[t]{2}{*}{$\mathrm{TiO}_{2} \mid \mathrm{CuInS}_{2}$} & 0.3 & 4 & & $<1$ & & $<1$ \\
\hline & 0.7 & 80 & & & & \\
\hline \multirow[t]{2}{*}{$\mathrm{TiO}_{2} \mid \mathrm{In}_{2} \mathrm{~S}_{3}$} & 0.4 & 5 & 0.55 & 5 & & - \\
\hline & 0.6 & 90 & 0.45 & 58 & & \\
\hline \multirow[t]{2}{*}{$\mathrm{In}_{2} \mathrm{~S}_{3} \mid \mathrm{CuInS}_{2}$} & 0.9 & 2 & 0.85 & 2 & 0.84 & 4 \\
\hline & 0.1 & 30 & 0.15 & 30 & 0.16 & 30 \\
\hline \multirow[t]{2}{*}{$\mathrm{TiO}_{2}\left|\mathrm{In}_{2} \mathrm{~S}_{3}\right| \mathrm{CuInS}_{2}$} & 0.55 & 4 & 0.67 & 3.5 & 0.76 & 3.5 \\
\hline & 0.45 & 60 & 0.33 & 27 & 0.24 & 27 \\
\hline
\end{tabular}

Also the TRMC transients of $\operatorname{In}_{2} \mathrm{~S}_{3} \mid \mathrm{CuInS}_{2}$ heterojunctions show interesting features [Fig. 5(c)]. With $450 \mathrm{~nm}$ the $\mathrm{In}_{2} \mathrm{~S}_{3}$ layer is predominantly excited. Clear decreases of both signal height and lifetime are found for the double layer as compared to $\operatorname{In}_{2} \mathrm{~S}_{3}$ single layers, as shown in Fig. 4(b). Apparently, the charge carrier lifetime in $\mathrm{In}_{2} \mathrm{~S}_{3}$ is negatively affected by the deposition of the CIS. The interface with CIS introduces new recombination pathways for the electron-hole pairs generated in $\operatorname{In}_{2} \mathrm{~S}_{3}$, similar to processes 3-5 in Fig. 1(b).

However, $650 \mathrm{~nm}$ excitation of $\mathrm{In}_{2} \mathrm{~S}_{3} \mid \mathrm{CuInS}_{2}$ junctions predominantly leads to excitation of the CIS. Now the electron-hole lifetime is considerably longer compared to single CIS films. Accordingly, excitation of CIS leads to the electron-hole separation at the interface with $\operatorname{In}_{2} S_{3}$ [process 4 in Fig. 1(b)] in competition with the very fast recombination processes 2 and 3. In view of the large IPCE that are found for short-circuited solar cells, the electron transfer rate of process 4 must be much larger than the recombination rates of processes 2 and 3. The TRMC signals obtained by excitation of the $\mathrm{In}_{2} \mathrm{~S}_{3}$ at $450 \mathrm{~nm}$ and CIS at $650 \mathrm{~nm}$ are identical. In both cases charge separation occurs, resulting in an electron in $\operatorname{In}_{2} \mathrm{~S}_{3}$ and a hole in CIS.

\section{Triple layers}

For the three-layer configuration, as involved in photovoltaic devices, the influence of the wavelength and the intensity of the laser light on the microwave conductivity has been studied and the results are shown in Figs. 6(a) and 6(b), respectively. The TRMC signals always show a biexponential decay.

With $300 \mathrm{~nm}$ laser pulses only $\mathrm{TiO}_{2}$ is excited, yielding TRMC signals similar to bare $\mathrm{TiO}_{2}$ and to $\mathrm{TiO}_{2} \mid \mathrm{In}_{2} \mathrm{~S}_{3}$ double layers. Most strikingly, excitation of triple layers at 450 or $650 \mathrm{~nm}$ yields TRMC signals comparable to $\mathrm{In}_{2} \mathrm{~S}_{3} \mid \mathrm{CuInS}_{2}$ double layers, as shown in Figs. 5(c) and 6(a). This similarity indicates that charge separation exclusively takes place at the interface between $\operatorname{In}_{2} \mathrm{~S}_{3}$ and $\mathrm{CuInS}_{2}$. The presence of $\mathrm{TiO}_{2}$ does not affect the lifetime of the charge carriers; there is no charge separation between the $\mathrm{TiO}_{2}$ and $\mathrm{In}_{2} \mathrm{~S}_{3}$ in the triple layer configuration. Accordingly, under open circuit conditions, as is the case in TRMC experiments, process 6 of Fig. 1(b) does not occur or does not lead to prolongation of the carrier-separation lifetime. Varying the laser intensity over two orders of magnitude reveals a clear superlinear dependence of the TRMC signal, as shown in Fig. 6(b). This indicates saturation of electron or hole traps, as has been observed before. ${ }^{19}$ Known acceptor states in CIS are copper vacancies and copper on indium sites at 0.1 and $0.15 \mathrm{eV}$ above the valence band, respectively. ${ }^{29}$ For $\operatorname{In}_{2} \mathrm{~S}_{3}$, trap levels are reported at 0.29 and $0.35 \mathrm{eV}$ below the conduction band. ${ }^{24}$

From the high IPCE values [Fig. 2(b)] for triple layer configurations, one can conclude that under short circuit condition, almost all incident photons yield electrons in the external circuit. This situation is very different when open circuit condition applies. In that case the charge separation lifetime has two characteristic time constants of 3.5 and 27 ns. Furthermore, it should also be realized that immobilization (trapping) of charge carriers gives rise to the decay of TRMC signals but does not need to affect the carrier collection efficiency.

\section{CONCLUSIONS}

The formation and decay of charges in $\mathrm{TiO}_{2}\left|\mathrm{In}_{2} \mathrm{~S}_{3}\right| \mathrm{CuInS}_{2}$ triple layered systems, prepared by spray pyrolysis and ALD, along with the individual layers and double layer combinations have been studied with timeresolved microwave conductivity. Excitation of single $\mathrm{TiO}_{2}$ and $\operatorname{In}_{2} \mathrm{~S}_{3}$ layers leads to the formation of long-lived mobile charge carriers. The derived carrier mobilities of 1.3 and $5.2 \mathrm{~cm}^{2} \mathrm{~V}^{-1} \mathrm{~s}^{-1}$ for anatase $\mathrm{TiO}_{2}$ and $\mathrm{In}_{2} \mathrm{~S}_{3}$, respectively, agree well with the literature values and underline the excellent quality of the deposited materials. TRMC signals of $\mathrm{CuInS}_{2}$ show a fast decay within the response time (1 ns) of the setup. 


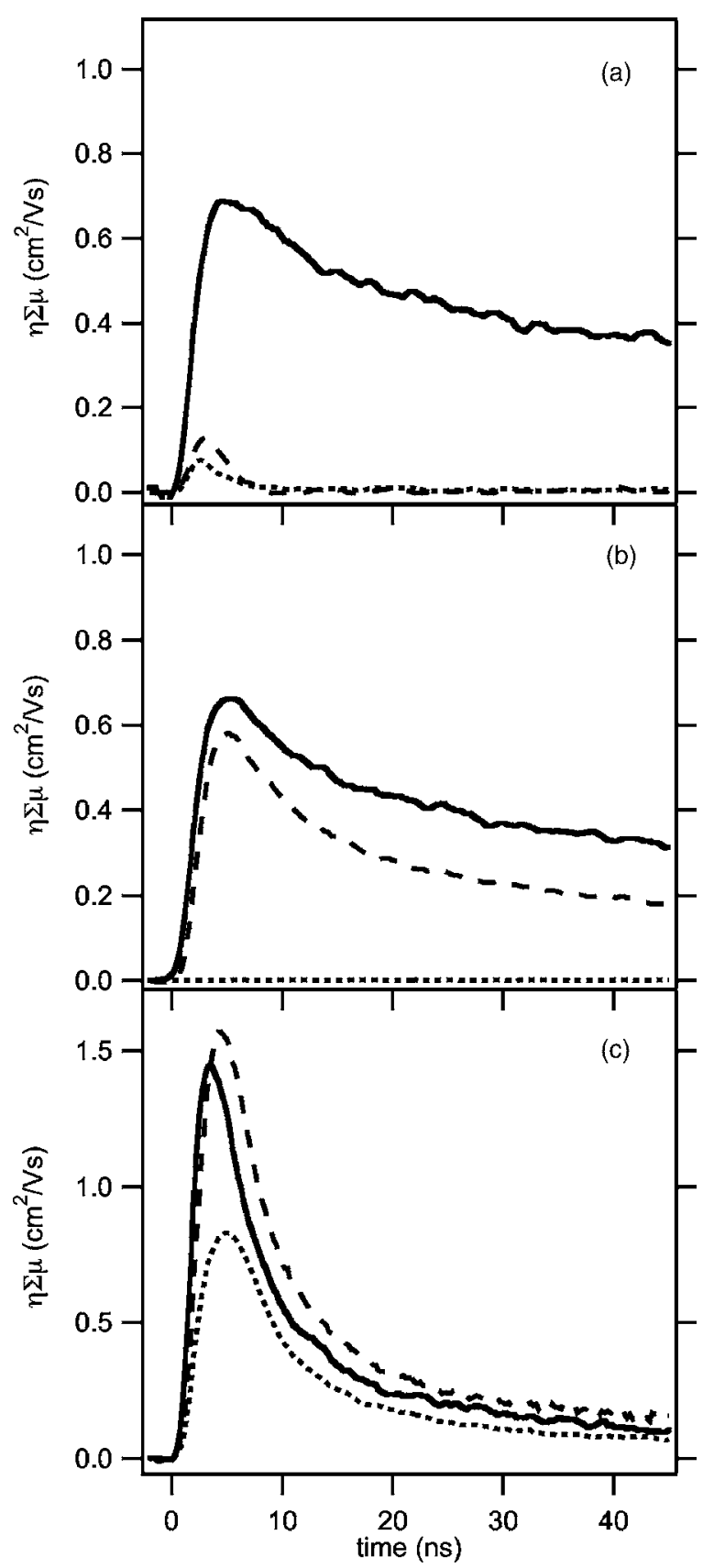

FIG. 5. TRMC response of double layers of $\mathrm{TiO}_{2} \mid \mathrm{CuInS}_{2}$ (a), $\mathrm{TiO}_{2} \mid \mathrm{In}_{2} \mathrm{~S}_{3}$ (b), and $\mathrm{In}_{2} \mathrm{~S}_{3} \mid \mathrm{CuInS}_{2}$ (c) at $300 \mathrm{~nm}$ (solid), $450 \mathrm{~nm}$ (dashed), and $650 \mathrm{~nm}$ (dotted) at an incident intensity of $20 \mu \mathrm{J} / \mathrm{cm}^{2}$ pulse.

For $\mathrm{TiO}_{2} \mid \mathrm{CuInS}_{2}$ double layers, the electron-hole recombination is even enhanced with respect to that in single $\mathrm{CuInS}{ }_{2}$ layers. However, when an $\operatorname{In}_{2} \mathrm{~S}_{3}$ buffer layer is applied, charge carriers generated in $\mathrm{CuInS}_{2}$ are separated quickly at the $\operatorname{In}_{2} \mathrm{~S}_{3} \mid \mathrm{CuInS} \mathrm{S}_{2}$ interface, which leads to a substantial increase of the charge carrier lifetime as compared to single $\mathrm{CuInS}_{2}$ films. Furthermore, the recombination kinetics of $\mathrm{TiO}_{2}\left|\mathrm{In}_{2} \mathrm{~S}_{3}\right| \mathrm{CuInS}_{2}$ junctions resembles those of $\mathrm{In}_{2} \mathrm{~S}_{3} \mid \mathrm{CuInS}_{2}$ heterojunctions, showing that $\mathrm{TiO}_{2}$ is not involved in the charge separation process.

The present TRMC study shows that the photoresponse in $\mathrm{TiO}_{2} \mid \mathrm{CuInS}_{2}$ heterojunctions is low due to the fast interfacial recombination. This recombination can be suppressed
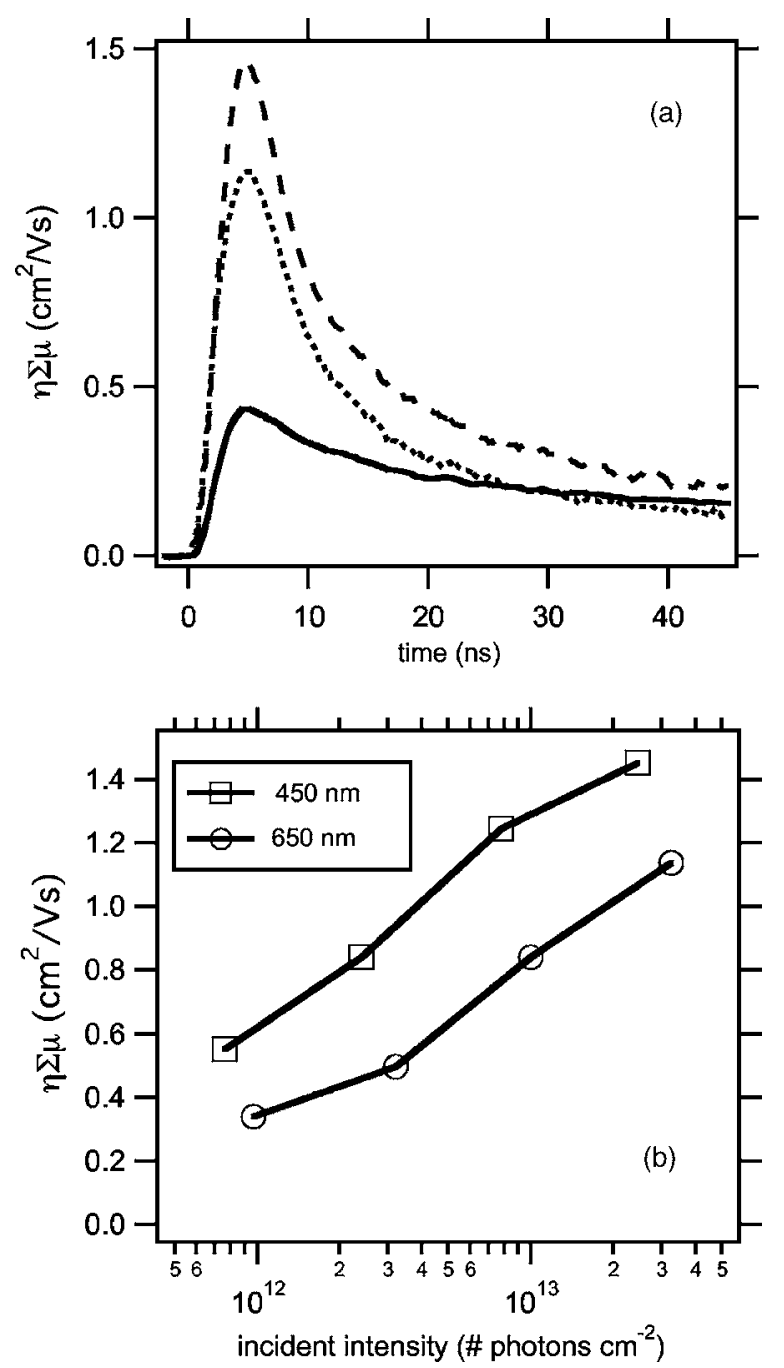

FIG. 6. TRMC response of triple layer $\mathrm{TiO}_{2}\left|\mathrm{In}_{2} \mathrm{~S}_{3}\right| \mathrm{CuInS}_{2}$ at $300 \mathrm{~nm}$ (solid), $450 \mathrm{~nm}$ (dashed), and $650 \mathrm{~nm}$ (dotted) at an incident intensity of $20 \mu \mathrm{J} / \mathrm{cm}^{2}$ pulse (a) and the dependency of the maximum of the $\eta \Sigma \mu$ signal as function of the incident intensity (b).

by applying an $\mathrm{In}_{2} \mathrm{~S}_{3}$ buffer layer. These findings explain the current-voltage behavior of solar cells made from these materials very well. Our findings are not uniquely related to $\mathrm{CuInS}_{2}$ and may also apply to other members of the chalcogenide family. Clearly TRMC is a unique and convenient method to study the fundamental optoelectronic processes at semiconductor interfaces.

${ }^{1} \mathrm{~S}$. Siebentritt and U. Rau, Wide-Gap Chalcopyrites (Springer, Berlin, 2006).

${ }^{2}$ M. Nanu, J. Schoonman, and A. Goossens, Adv. Mater. (Weinheim, Ger.) 16, 453 (2004).

${ }^{3}$ C. Levy-Clement, R. Tena-Zaera, M. A. Ryan, A. Katty, and G. Hodes, Adv. Mater. (Weinheim, Ger.) 17, 1512 (2005).

${ }^{4}$ K. Ernst, A. Belaidi, and R. Konenkamp, Semicond. Sci. Technol. 18, 475 (2003).

${ }^{5}$ R. Konenkamp, L. Dloczik, K. Ernst, and C. Olesch, Physica E (Amsterdam) 14, 219 (2002).

${ }^{6}$ C. Levy-Clement, A. Katty, S. Bastide, F. Zenia, I. Mora, and V. MunozSanjose, Physica E (Amsterdam) 14, 229 (2002).

${ }^{7}$ J. Wienke, M. Krunks, and F. Lenzmann, Semicond. Sci. Technol. 18, 876 (2003).

${ }^{8}$ G. Yu, J. Gao, J. C. Hummelen, F. Wudl, and A. J. Heeger, Science 270, 1789 (1995).

${ }^{9}$ T. Hahn et al., J. Phys. Chem. Solids 66, 1899 (2005). 
${ }^{10}$ S. Siebentritt, Thin Solid Films 403, 1 (2002).

${ }^{11}$ M. Nanu, J. Schoonman, and A. Goossens, Adv. Funct. Mater. 15, 95 (2005).

${ }^{12}$ M. Nanu, L. Reijnen, B. Meester, J. Schoonman, and A. Goossens, Chem. Vap. Deposition 10, 45 (2004).

${ }^{13}$ J. A. Naber and D. P. Snowden, Rev. Sci. Instrum. 40, 1137 (1969).

${ }^{14}$ M. P. de Haas and J. M. Warman, Chem. Phys. 73, 35 (1982).

${ }^{15}$ M. Kunst and G. Beck, J. Appl. Phys. 60, 3558 (1986).

${ }^{16}$ M. Kunst, F. Wunsch, D. F. Marron, and A. Meeder, Thin Solid Films 451-452, 152 (2004).

${ }^{17}$ T. J. Savenije, P. van Veenendaal, M. P. de Haas, J. M. Warman, and R. E. I. Schropp, J. Appl. Phys. 91, 5671 (2002).

${ }^{18}$ J. E. Kroeze, T. J. Savenije, M. J. W. Vermeulen, and J. M. Warman, J. Phys. Chem. B 107, 7696 (2003).

${ }^{19}$ J. E. Kroeze, T. J. Savenije, and J. M. Warman, J. Am. Chem. Soc. 126, 7608 (2004).

${ }^{20}$ M. I. Alonso, K. Wakita, J. Pascual, M. Garriga, and N. Yamamoto, Phys. Rev. B 63, 075203 (2001).
${ }^{21}$ T. J. Savenije, M. P. de Haas, and J. M. Warman, Z. Phys. Chem. (Munich) 2, 201 (1999).

${ }^{22}$ L. Forro, D. Chauvet, D. Emin, L. Zuppiroli, H. Berger, and F. Levy, J. Appl. Phys. 75, 633 (1994).

${ }^{23}$ M. Paulraj, S. Ramkumar, P. R. Amjith, T. T. John, P. M. Ratheeshkumar, C. Sudhakartha, K. P. Vijayakumar, and K. G. M. Nair, J. Phys. IV 125, 469 (2005).

${ }^{24}$ A. A. El Shazly, D. Abd Elhady, H. S. Metwally, and M. A. M. Seyam, J. Phys.: Condens. Matter 10, 5943 (1998).

${ }^{25}$ D. C. Look and J. C. Manthuruthil, J. Phys. Chem. Solids 37, 173 (1976).

${ }^{26}$ R. Scheer, T. Walter, H. W. Schock, M. L. Fearheiley, and H. J. Lewerenz, Appl. Phys. Lett. 63, 3294 (1993).

${ }^{27}$ P. M. Sirimanne, Y. Yasaki, N. Sonoyama, and T. Sakata, Mater. Chem. Phys. 78, 234 (2003).

${ }^{28}$ Y. Yasaki, N. Sonoyama, and T. Sakata, J. Electroanal. Chem. 469, 116 (1999).

${ }^{29}$ M. Nanu, F. Boulch, J. Schoonman, and A. Goossens, Appl. Phys. Lett. 87, $242103(2005)$ 